\title{
Co-Creation Of Value In Business-To-Business Services
}

\author{
Yoshiaki Watanabe, University of Tsukuba, Japan
}

\begin{abstract}
Although marketing researchers pay increasing attention to the co-creation of value, switching costs and customer share, not much is known about their interrelationships.

This study extracts prior research by developing a conceptual framework linking all of these constructs in the business-to-business (BtoB) service setting, including the detailed examination of the process of co-creation of value. On the basis of the achievements in services marketing and relationship marketing, this study hypothesises that co-creation of value mediates switching costs and that indirect customer values and co-creation of value are positively related to customer share. The author tests the hypotheses on data obtained from corporate managers in charge of their banking relationship. The results of the study support most of the hypotheses and, in particular, confirm the mediating role of co-creation of value in a BtoB context.
\end{abstract}

Keywords: Services Marketing; Co-Creation of Value; Switching Costs; Customer Share

\section{INTRODUCTION}

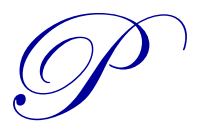

rior research has examined the relationships within subsets of theses constructs, mainly in the business-to-consumer (BtoC) environment (Lam, Shanker, Erramilli, \& Murphy, 2004). Gao, Sirgy, and Bird (2005) argue that current marketing literature provides limited insights on value assessment by customers and that much of existing marketing research on customer value has been conducted in consumer marketing, rather than business-to-business (BtoB) marketing. Eggert and Ulaga $(2008,2010)$ also confirm that existing marketing insights on customer share largely stem from consumer research in the BtoC environment, rather than the BtoB environment. For instance, Eggert and Ulaga (2008) report that, out of 29 empirical studies, 20 appear within the BtoC context, examining previous empirical studies of customer share by searching the EBSCO database for scholarly articles with such terms as 'customer share' and 'share of purchase'.

Customer re-purchase intention has been examined as the main purpose of marketing initiatives in the BtoC environment by a number of marketing researchers over the years (Mittal, Ross, \& Baldasare, 1998; Jones, Mothersbaugh, \& Beatty, 2000; Zhang, Fang, Wei, Ramsey, McCole, \& Chen, 2011). The same situation is also observed in BtoB marketing studies (Patterson \& Spreng, 1997; Spreng, Shi, \& Page, 2009; Kellar \& Preis, 2011).

However, the author would argue that in the BtoB environment, increase of customer share, which is also referred to as 'wallet share of customer', is more critical than customer re-purchase intention or customer retention because, in the BtoB business context, a corporate customer tends to maintain a long-term relationship with its supplier base and to re-purchase from those suppliers with a different volume share for each supplier at a time. It is customer share that an enterprise needs to maximise in the BtoB business context. Therefore, in this study, the ultimate goal of marketing activities is defined as the increase of customer share, rather than re-purchase intention or customer retention.

The concept of co-creation of value in the Service-Dominant (S-D) logic developed by Vargo \& Lusch (2004, 2008a, 2008b, and 2011; Lusch \& Vargo, 2006) has been well received by the academic marketing community on a global basis, including Japan. However, little has been done to address its relationship with switching costs and customer share in the BtoB environment, particularly in the services marketing arena. In addition, past research has 
not fully examined the processes of co-creation of value in detail. The S-D logic focuses so much on the moment of co-consumption at the point of and after service encounter that the S-D logic does not fully cover the preparation stage in the process of co-creation of value (Toya, 2013).

This study extracts prior research by developing a conceptual framework linking all of these constructs in the BtoB service setting, including a detailed examination of the process of co-creation of value. On the basis of the marketing achievements in services marketing, co-creation of value, switching costs, customer value and customer share, this study hypothesises that co-creation of value mediates switching costs and that customer indirect value and co-creation of value are positively related to customer share. To test the hypotheses, the author chose the financial services industry in the BtoB environment because it embodies some common characteristics considered important for BtoB services, which are related to its wide variety of service offerings.

The author tests the hypotheses on data obtained from corporate managers in charge of their relationships with their banks. The author modified its original questionnaire after receiving feedback from corporate managers and bank managers about the relevance of each question in the questionnaire. The results of the analyses support most of the hypotheses and, in particular, confirm the mediating role of the co-creation of value in the BtoB context.

\section{LITERATURE REVIEW AND HYPOTHESES DEVELOPMENT}

In developing the conceptual framework, as shown in Figure 1, the author reviewed literature on services marketing, co-creation of value, customer value, switching costs and customer share. On the basis of this review, the author defines the key constructs of the hypotheses and describes the theoretical grounds that support the hypotheses in this study.

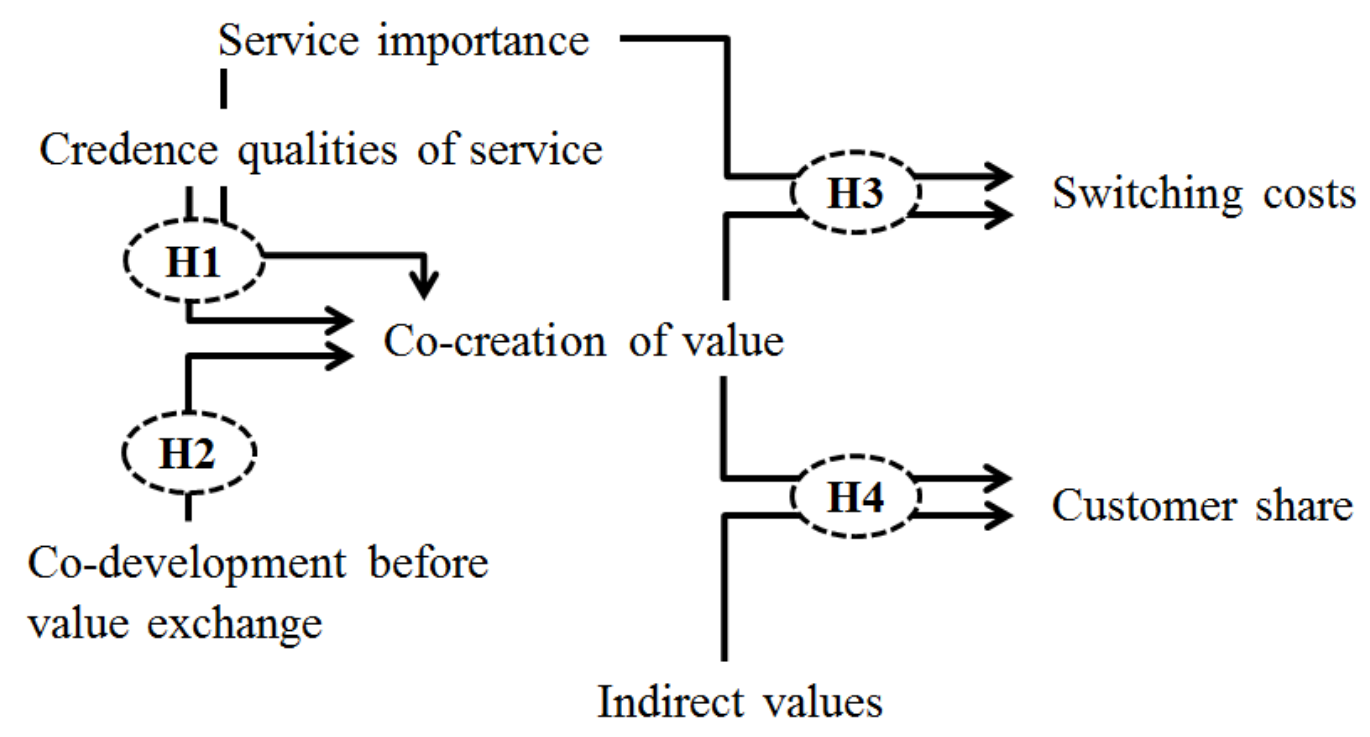

Figure 1: Conceptual Framework

\section{Services Marketing And Co-Creation Of Value}

In services marketing, goods and services are grouped into three categories - search qualities, experience qualities and credence qualities (Zeithaml \& Bitner, 1996). Search qualities have attributes that a customer can determine before purchasing. Experience qualities have attributes that a customer can discern only after purchase or during consumption. Credence qualities have attributes that a customer finds very difficult or impossible to evaluate, even after purchase or consumption. Zeithaml and Bitner (1996) argue that most services are high in either experience qualities or credence qualities. 
Vargo \& Lusch (2008a) argue that value creation in the concept of co-creation of value is interactional and that an enterprise and its customer create more value together. In the BtoB business context, some services are rather simple, which might represent less co-creation of value, and some services are rather complex which might represent larger co-creation of value. The author hypothesises that services with higher credence qualities are associated with larger co-creation of value.

Because the level of credence qualities of each service is judged by each customer, an enterprise cannot control it by itself. However, if there were a meaningful correlation between credence qualities and co-creation of value, then it would be important for an enterprise to understand which services have higher credence qualities; in other words, which services could have a larger impact on the co-creation of value. Such understanding will enable an enterprise to effectively prioritise its limited resources when implementing co-creation of value with its customers.

When the concept of credence qualities and its impact on co-creation of value are considered in the BtoB financial services, investment banking services in mergers and acquisitions (M\&A) support would represent a good example. M\&A support certainly has very high credence qualities because the corporate customer has little visibility of the service level of the M\&A support that its bank would provide until the very end of the service. To make such M\&A support more successful, it is critical for the bank and the customer to develop a mutual understanding of the market environment of the customer's business and strategy and ensure effective selection of M\&A target companies and the appropriate approach to candidate companies, creating larger value from the relationship between the bank and its customer.

Similar to credence qualities, the importance of each service is judged by each customer; therefore, an enterprise cannot control it by itself. However, if service importance mediates co-creation of value along with credence qualities, then it would be important for an enterprise to understand which services are more important to its customers. Such understanding will help an enterprise to effectively implement co-creation of value with its customers.

Hypothesis 1: Services with higher credence qualities and higher service importance are associated with larger cocreation of value.

\section{Co-Development And Co-Creation Of Value}

The detailed processes of co-creation of value in the Service-Dominant (S-D) logic, originally developed by Vargo \& Lusch (2004), have yet to be fully examined. In the concept of co-creation of value, it is argued that, in principle, 'value-in-use' should be more focused than 'value-in-exchange' and that such 'value-in-use' could be maximised by the co-work between an enterprise and its customers. In such an argument, the impact of codevelopment 'before value exchange' on the overall co-creation of value tends not to be fully examined from the perspective of the processes involved on value co-creation. S-D logic focuses so much on the moment of coconsumption at the point of and after service encounter that it does not fully address the impact of the preparation stage of co-creation of value (Toya, 2013).

Lusch \& Vargo (2006) recognise that there are two components of value co-creation - that of value and codevelopment (or co-production). With regard to the first component of co-creation of value, it is argued that value can only be created with and determined by a customer in the 'consumption' stage, as 'value-in-use'. As for the second component of co-development, it is argued that co-development occurs through co-design or shared production of related goods with customers and any partners in the value network. Such an argument by Lusch \& Vargo (2006) still does not fully address the issue of the appropriate timing of co-development; in particular, the importance of the preparation stage and its impact on the overall co-creation of value, although it suggests the criticality of partner choice in the process of co-development.

Vargo \& Lusch (2008a) modified all ten FPs (fundamental premises) in their S-D logic. In particular, they changed FP 6 from 'the customer is always a co-producer' to 'the customer is always a co-creator of value', implying that value creation is interactional between an enterprise and its customers. Although such change or modification 
captures the difference between co-development and co-creation of value, it still does not fully address the issue of the appropriate timing of co-development.

Although there are a number of research papers on co-creation of value, little has been explored about the timing of co-development to optimise co-creation of value. Although Frow, Payne, and Storbacka (2011) develop a conceptual framework for value co-creation, the effective timing of co-development remains unclear. Grönroos (2005), however, divides value co-creation into a preparation stage and a service-in-use stage and argues for appropriate marketing activities during each stage, taking a mobile phone service as an example. In a similar context, a conceptual model is provided by Fujikawa, Akutsu, and Ono (2012) that captures the timing of co-development more clearly and helps the author to build a conceptual model on the timing of co-development, as shown in Figure 2.

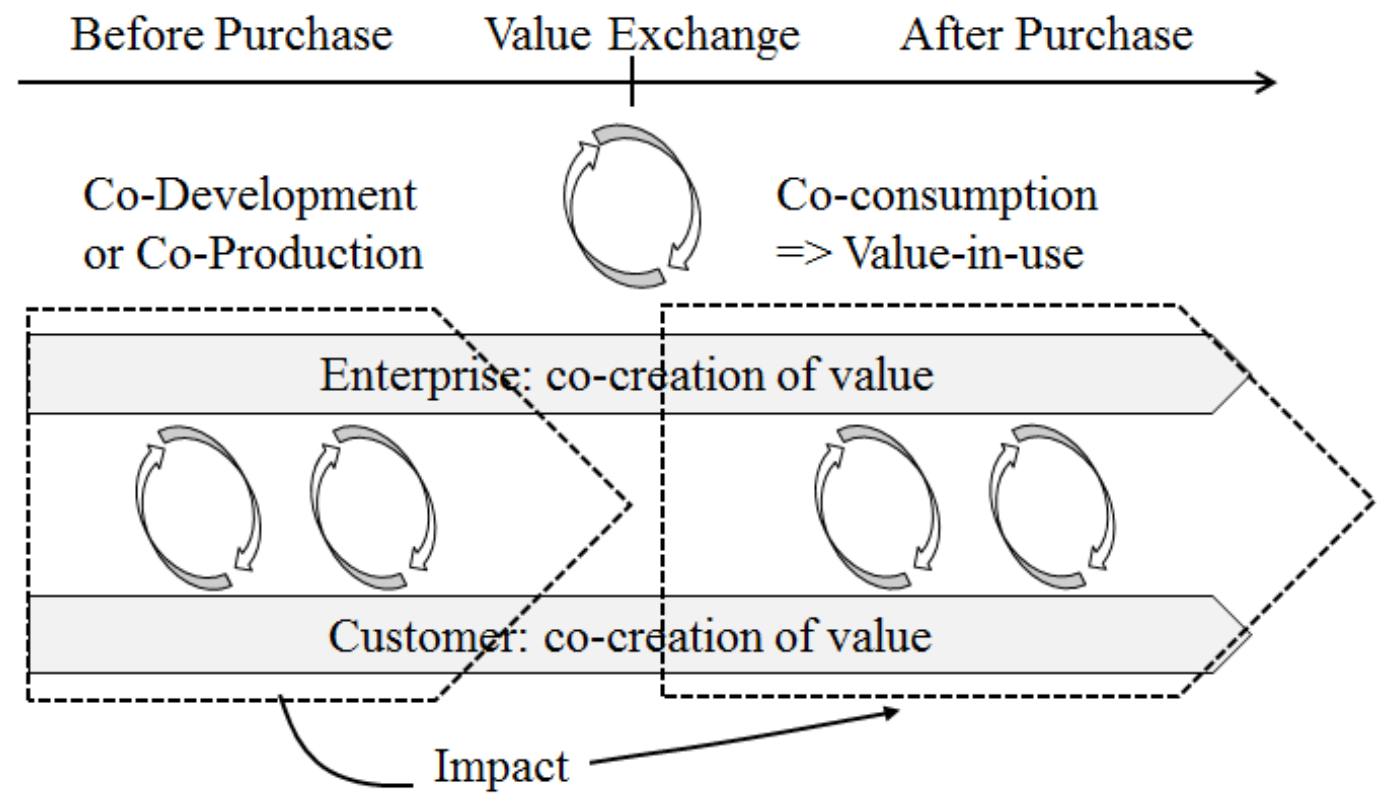

Source: Slightly modified from Fujikawa, Akutsu, and Ono (2012)

Figure 2: Conceptual Model Of Co-Development

Based on this conceptual model, the author hypothesises that co-creation of value would be larger in the case where co-development is implemented in the preparation stage prior to value exchange, considering that the service content is already defined at the point of value exchange.

Hypothesis 2: Co-creation of value is larger in the case where co-development is implemented prior to value exchange.

Applying this hypothesis to BtoB financial services, a loan covenant in a bank loan would represent a good example. A loan covenant is an obligation in a commercial loan that requires the borrower to fulfil certain conditions during the loan term. Violation of a covenant normally results in a default on the loan or some penalties. From the borrower's perspectives, it is important to understand the priorities of the covenants of the bank well in advance of the loan agreement because it might be able to modify or even eliminate covenants that would be difficult to fulfil but have lower priority for the bank. From the bank's perspectives, it is important to understand the potential impact of each covenant to avoid covenants that significantly undermine the future growth of the borrower. Therefore, it would be critical for both parties to co-work on the covenants in advance, before the contract exchange, to create larger value from the relationship between them. 


\section{Switching Costs And Co-Creation Of Value}

Switching costs can be categorised as economic costs, evaluation costs, learning costs, set-up costs and others (Burnham, Frels, \& Mahajan, 2003). Little research has examined the relationship between switching costs and co-creation of value. However, it can be easily assumed that if an enterprise can successfully provide higher cocreation of value with its customers, then it would make it more difficult for the customers to switch to another supplier (i.e., higher switching costs), assuming that not every enterprise manages co-creation of value in the same way. In addition, such switching costs would be even larger for services with higher importance from the customer's perspective because a customer would find it more difficult to switch supplier when the service is more important. Therefore, the author hypothesises that co-creation of value and service importance are associated with higher switching costs.

Hypothesis 3: Co-creation of value and service importance are associated with higher switching costs.

Applying this hypothesis to BtoB financial services, it is suggested that a bank that is trying to obtain a main bank position, or a main supplier position at a customer, should target services with large co-creation of value potential and small switching costs, as shown in Figure 3. Once an enterprise articulates and demonstrates the power of co-creation of value in services with small switching costs, it should be able to convince the customer to upgrade its supplier position for other services. Based on interviews with bank managers, trade finance is assumed to be a good example of such a service.

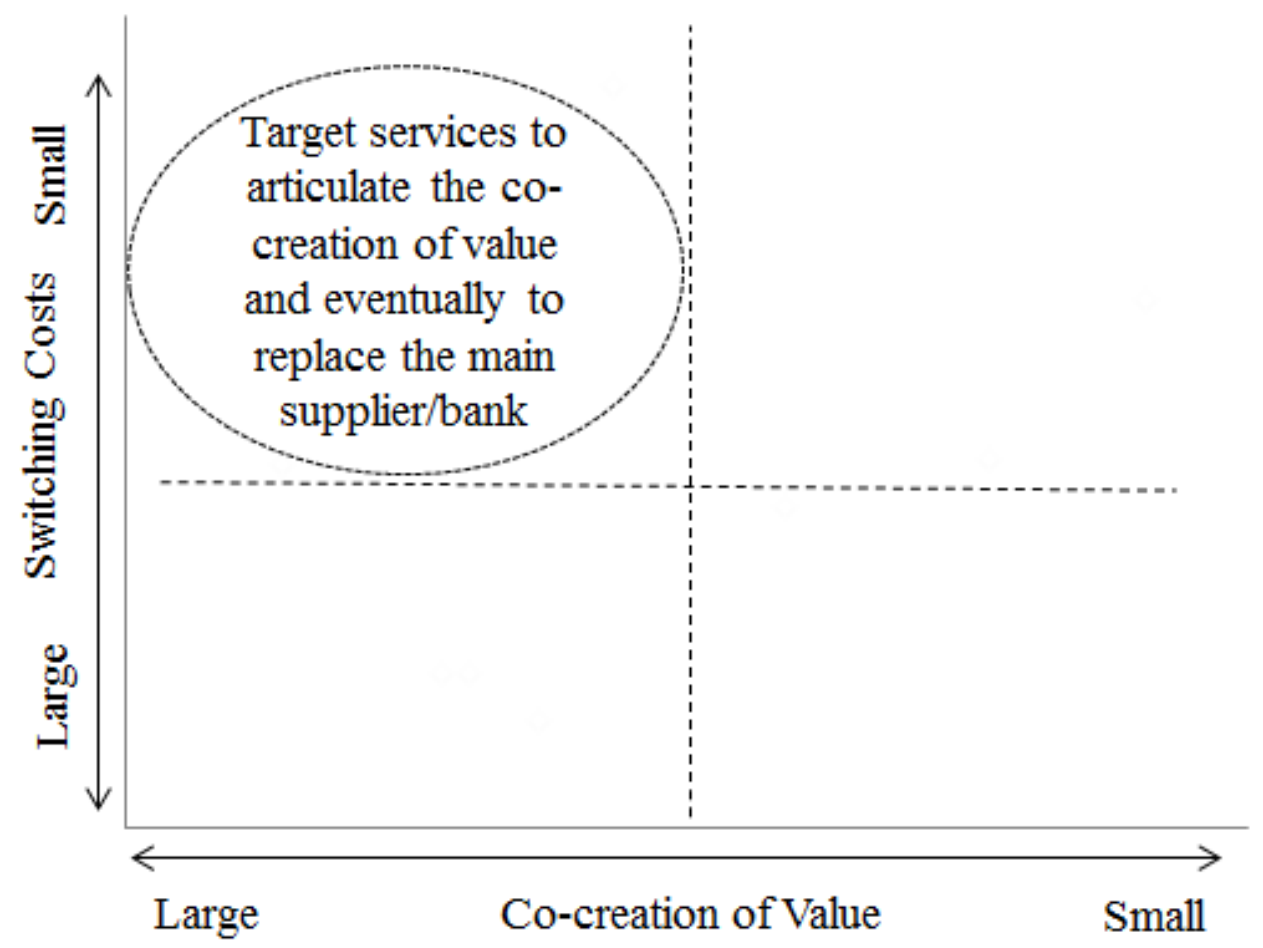

Figure 3: Target Services For A Main Supplier Position

\section{Customer Share And Customer Value}

Gao et al. (2005) define that BtoB customer value has two components: 1) relational antecedents of value from a long-term relationship between a supplier company and its corporate customer and 2) a transactional view of value from each transaction, emphasising the significance of relational antecedents of value in the BtoB environment. 
Similar to such recognition of transactional views of value and relational antecedents of value, Walter, Ritter and Gemünden (2001) distinguish business relationships into direct values and indirect values, arguing that direct values that are mainly associated with profit and volume functions have an immediate effect on partner firms and that indirect values that are mainly associated with access, market, innovation and other functions have a slow or gradual effect on partner firms. in Figure 4.

Building on this distinction, Walter et al. (2001) also define four different customer relationships, as shown

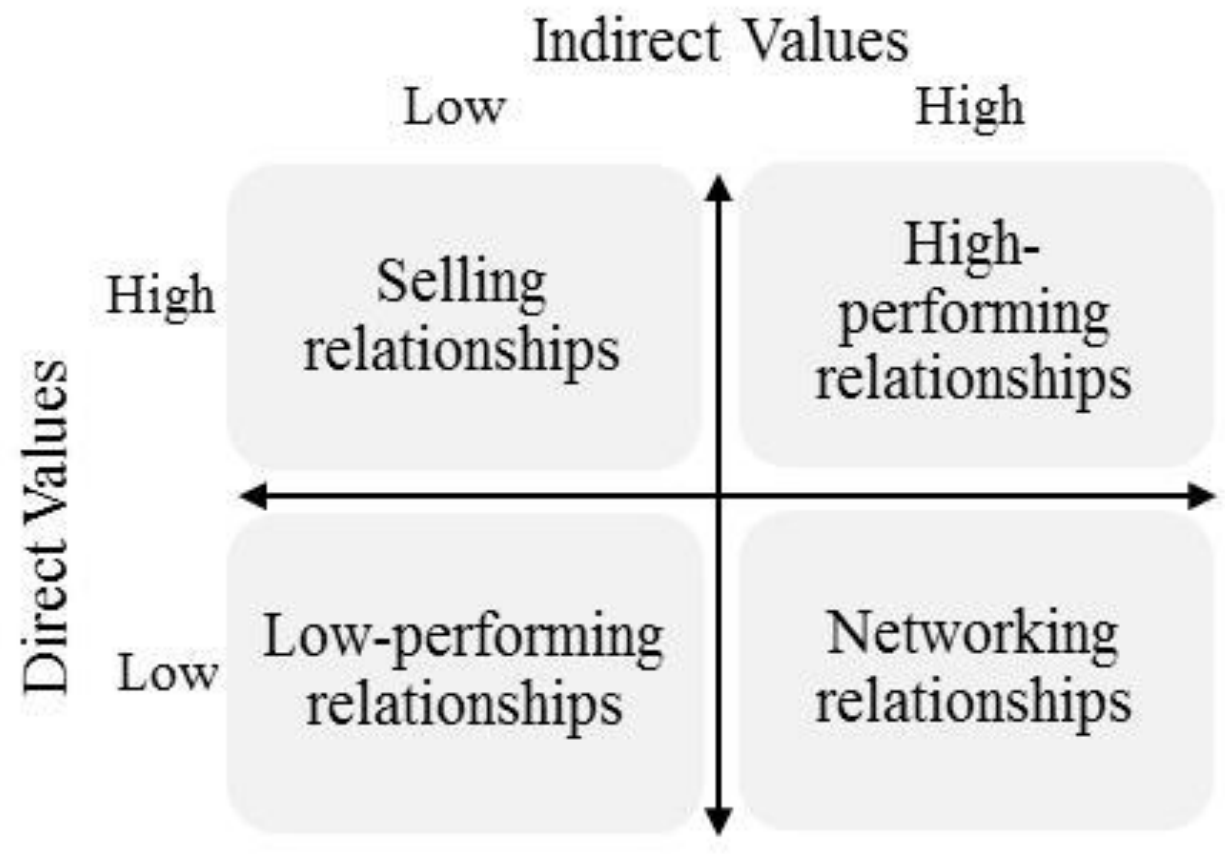

Source: Slightly modified from Walter et al. (2001)

Figure 4: Four Different Customer Relationships

Interestingly, the 'networking relationships' that have high indirect value and low direct value are positioned more positively than 'selling relationships' that have low indirect value and high direct value because 'Networking relationships have a strong impact on value creation in connected relationships' (Walter et al., 2001, p. 374). Applying this customer segmentation to the BtoB environment, a customer re-purchasing from existing suppliers will consider business relationship with a long-term perspective that places higher priority on indirect values that have a larger impact in the long run than on direct values that basically represent the current price and service level. This could mean that an enterprise that provides larger indirect value would achieve higher customer share in the long run. Therefore, the author hypothesises that indirect values, or relational antecedents of value, are associated with higher customer share because corporate customers, when considering a long-term BtoB relationship, place a higher priority on relational antecedents of value than on the transactional view of value.

If an enterprise provides larger co-creation of value in its services with its customers, then it should be able to differentiate itself from its competitors, assuming that not every enterprise manages co-creation of value in the same way, as already discussed in relation to Hypothesis 3. Combining co-creation of value and indirect values effectively, an enterprise should be able to achieve higher customer share in the BtoB relationship. Therefore, the author puts forward the following hypothesis:

Hypothesis 4: Indirect values and co-creation of value are associated with higher customer share. 


\section{CONCEPTUALISATION OF KEY CONSTRUCTS}

To test these hypotheses, the author decided to use a quantitative method by sending a questionnaire to corporate managers in charge of their banking relationships. The author designed the questionnaire with conceptualised measures of the relevant constructs, primarily based on scales taken from previous studies.

\section{Conceptualisation: Co-Creation Of Value}

One of the remaining issues of co-creation of value in the S-D logic is its conceptualisation (Inoue, 2013). In this study, co-creation of value is conceptualised by its three dimensions (monetary value, knowledge value and emotional value), which are recently developed by Toya (2013), building on a model by Normann and Ramirez (1993). Monetary value is defined as 'value that can be easily converted to money and that is measured by an enterprise and its customers'; knowledge value is defined as 'value that accumulates with the stakeholders in cocreation of value and that contributes to the increase of co-creation of value over time'; and emotional value is defined as 'value that comes from emotion such as trust in others, deriving from a continuous relationship between an enterprise and its customer'. Table 1 presents the results of conceptualisation of co-creation of value and its three dimensions.

Table 1: Co-Creation Of Value

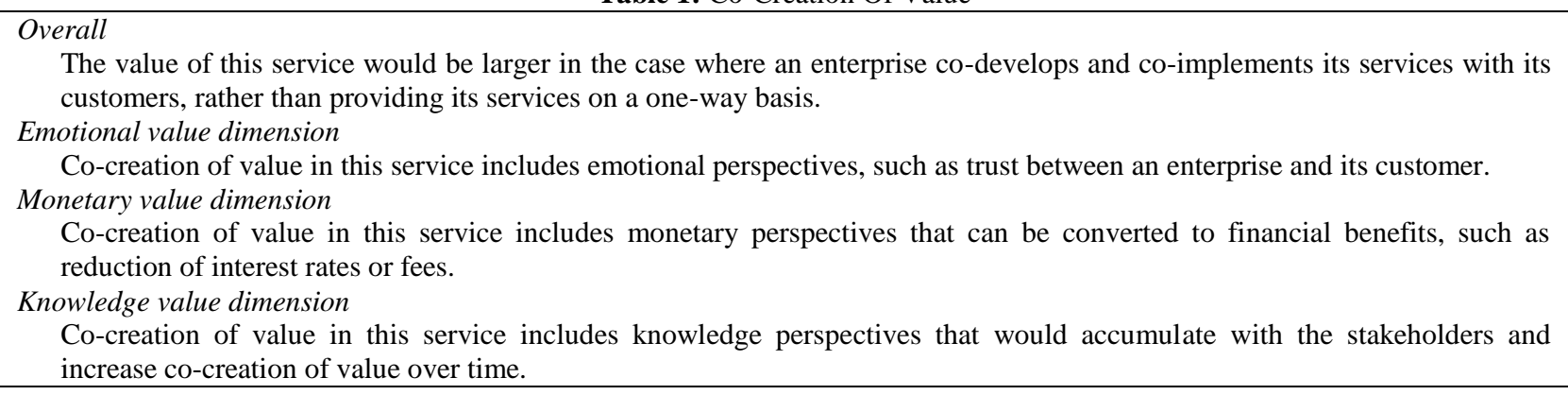

\section{Conceptualisation: Switching Costs}

Switching costs are conceptualised by four dimensions (economic, evaluation, learning and set-up costs) which are developed by Burnham et al. (2003). Although Burnham et al. (2003) suggest other dimensions for switching costs, they are not used in this study because they are judged to be less relevant in the BtoB environment.

Table 2 presents the results of conceptualisation of the four dimensions of switching costs.

Table 2: Switching Costs

\footnotetext{
Learning costs

Learning to use the service offered by a new service provider would take time.

Economic costs

I worry that the service offered by other service providers won't work as well as the current service provider.

Evaluation costs

Comparing the benefits of the current service provider with the benefits of other service providers takes time and effort. Set-up costs

It takes time to go through the preparation steps of switching to a new service provider.
}

\section{Conceptualisation: Indirect Values}

Indirect values in this study are conceptualised by the four dimensions, which are reliability, empathy, responsiveness, tangibles, in the SERVQUAL scale developed by Parasuraman, Berry and Zeithaml (1991). Although the SERVQUAL model has another dimension of assurance, it was dropped in this study because the author received feedback from corporate managers that this dimension is less relevant in the BtoB environment. Table 3 presents the results of conceptualisation of the four dimensions of indirect values. 
Table 3: Indirect Values

Reliability
Our company believes in the information the main supplier provides us.
Empathy
The main service provider deeply understands the specific situations of our company's business related to this service.
Responsiveness
The main service provider promptly responses to the inquiries from our company.
Tangibles
The main service provider supports its service by effective computer system.

\section{RESEARCH DESIGN}

Pre-testing of the questionnaire was conducted during two face-to-face interviews with senior managers of commercial banks and four e-mail- and telephone-based responses from corporate managers who take charge of their banking relationships. In the questionnaire, the BtoB financial services are divided into eight services to fully cover the width of banking services to corporate customers to include domestic money transfer, yen deposit, Internet banking, trade finance, global cash management service (GCMS), investment banking services, and both short-term and long-term bank loans. Each respondent was asked to indicate their agreement or disagreement on each question for each of the eight services, using a seven-point scale with anchors of 'strongly agree' (1) and 'strongly disagree' (7).

With distribution support from a market research company, the questionnaire was sent to their database with the following four conditions: 1) each respondent must be a corporate manager who is in charge of their company's banking relationship, 2) each respondent must be in a non-financial industry to avoid respondents from banks and other financial institutions, 3) the number of the company employees must be 50 or more and 4) no respondent can be from a research company.

Two hundred and nine (209) valid and usable responses were received to analyse the interrelationships among key constructs in the research, using SPSS Statistics 22.0. Sample characteristics are reported in Table 4.

Table 4: Sample Characteristics $(n=209)$

\begin{tabular}{|c|c|c|c|c|c|}
\hline Gender & $\%$ & Age Group & $\%$ & Industry and Size of Employee & $\%$ \\
\hline Male & 93 & 30 to 34 yrs old & 5 & Mfg 100 to 200 employees & 7 \\
\hline \multirow[t]{11}{*}{ Female } & 7 & 35 to 39 yrs old & 17 & Mfg 200 to 300 employees & 5 \\
\hline & & 40 to 44 yrs old & 22 & Mfg 300 to 500 employees & 7 \\
\hline & & 45 to 49 yrs old & 19 & Mfg 500 to 1;000 employees & 10 \\
\hline & & 50 to 54 yrs old & 23 & Mfg $1 ; 000$ to $3 ; 000$ employees & 9 \\
\hline & & 55 to 59 yrs old & 14 & Mfg 3;000 to 5;000 employees & 2 \\
\hline & & & & Mfg over 5;000 employees & 9 \\
\hline & & & & Non-mfg; 300 to 500 employees & 13 \\
\hline & & & & Non-mfg; 500 to $1 ; 000$ employees & 9 \\
\hline & & & & Non-mfg; $1 ; 000$ to $3 ; 000$ employees & 12 \\
\hline & & & & Non-mfg; 3;000 to 5;000 employees & 5 \\
\hline & & & & Non-mfg; over 5,000 employees & 13 \\
\hline Total $^{\mathrm{a}}$ & 100 & & 100 & & 100 \\
\hline
\end{tabular}




\section{RESULTS AND IMPLICATIONS}

Before testing the hypotheses, reliability of the collected data was analysed. Reliability estimates for the scales were uniformly high, with Cronbach-alpha coefficients ranging from .854 to .926 (Cronbach, 1951).

The author performed statistical analyses to test the hypotheses in this study, including multiple regression analysis. When multiple regression analysis was conducted, the variance inflation factor (VIF) statistics confirmed that multicollinearity was not a problem for all the analyses in this study, as VIF scores were significantly below the recommended cut-off point of 10 (Menard, 1995; Curto \& Pinto, 2011). The author uses standardised beta coefficients for all analyses because they are directly comparable and, hence, can give better insight into the relative contribution of each variable (Eisingerich \& Bell, 2007).

Following are the analysis results for each of the four hypotheses and managerial implications from the perspectives of BtoB marketing strategy in the financial services.

Hypothesis 1: Services with higher credence qualities and higher service importance are associated with larger cocreation of value.

This hypothesis is weakly supported. The $r$ of the regression analysis for all the services that have cocreation of value as dependent variables, and service importance and credence qualities as independent variables, is only .357, although the two independent variables are statistically significant with high $t$-values, as shown in Table 5 . The result is affected by particularly lower $r$ in domestic transfer, yen deposit and Internet banking. This could suggest that the business linkage between banks and corporate customers is so intense that corporate customers have less ambiguity about the content of the financial services provided by their banks.

Table 5: Regression Analysis On Hypothesis 1

\begin{tabular}{lccccc} 
& \multicolumn{5}{c}{ Beta $^{\mathrm{b}}$ : } \\
Service & $\mathrm{R}^{\mathrm{a}}$ & $\begin{array}{c}\text { Bedence } \\
\text { Qualities }\end{array}$ & $\begin{array}{c}\text { Service } \\
\text { Importance }\end{array}$ & $\begin{array}{c}\text { t: Credence } \\
\text { Qualities }\end{array}$ & $\begin{array}{c}\text { t: Service } \\
\text { Importance }\end{array}$ \\
\hline AllServices & .357 & .207 & .302 & 9.033 & 13.173 \\
DomesticTransfer & .219 & .218 & .048 & 3.197 & .701 \\
YenDeposit & .296 & .259 & .157 & 3.887 & 2.354 \\
InternetBanking & .289 & .237 & .165 & 3.556 & 2.480 \\
TradeFinance & .429 & .086 & .419 & 1.364 & 6.652 \\
GCMS & .378 & .219 & .289 & 3.381 & 4.460 \\
I-Bank & .413 & .287 & .264 & 4.491 & 4.134 \\
ShortTermLoan & .356 & .136 & .344 & 2.073 & 5.247 \\
LongTermLoan & .379 & .126 & .364 & 1.951 & 5.642 \\
\hline
\end{tabular}

a. Predictors: (Constant), ServiceImportance, CredenceQualities

b. Dependent Variable: Co-creation of Value

Hypothesis 2: Co-creation of value is larger in the case where co-development is implemented prior to value exchange.

This hypothesis is barely supported. The $t$-TEST value to compare the average of the two scores - 1) the average of co-creation of value in the case where co-development is implemented before value exchange and 2) the average of co-creation of value without any specification of co-development timing) - is only $1.662(p=.097)$ for all the services combined. Table 6 presents the $t$-TEST value for all services. This could suggest that banks and corporate customers communicate with each other reasonably well in repeated service solicitation and purchases, including the preparation stage of service contracts. 
Table 6: $T$-TEST Value For Hypothesis 2

\begin{tabular}{lcccc} 
Service & Mean & $\begin{array}{c}\text { Std. } \\
\text { Deviation }\end{array}$ & $\mathrm{t}$ & $\begin{array}{c}\text { Sig. (2- } \\
\text { tailed) }\end{array}$ \\
\hline AllServices & .056 & 1.368 & 1.662 & .097 \\
DomesticTransfer & -.014 & 1.508 & -.138 & .891 \\
YenDeposit & .182 & 1.450 & 1.813 & .071 \\
InternetBanking & .057 & 1.496 & .555 & .580 \\
TradeFinance & .196 & 1.223 & 2.319 & .021 \\
GCMS & .048 & 1.259 & .550 & .583 \\
I-Bank & -.067 & 1.288 & -.752 & .453 \\
ShortTermLoan & .019 & 1.355 & .204 & .838 \\
LongTermLoan & .024 & 1.339 & .258 & .796
\end{tabular}

Hypothesis 3: Co-creation of value and service importance is associated with higher switching costs.

This hypothesis is weakly supported for all the services combined. The $r$ of the multiple regression analysis for all services that have switching cost as a dependent variable, and co-creation of value and service importance as independent variables, is only .366, although $t$-values are high for the two independent variables (14.594 and 2.208 , respectively), as shown in Table 7.

Table 7: Regression Analysis On Hypothesis 3

\begin{tabular}{lccccc} 
Service & $\mathrm{R}^{\mathrm{a}}$ & $\begin{array}{c}\text { Beta }{ }^{\mathrm{b}} \text { : Co- } \\
\text { creation } \\
\text { of Value }\end{array}$ & $\begin{array}{c}\text { Beta }{ }^{\mathrm{b}} \text { Service } \\
\text { Importance }\end{array}$ & $\begin{array}{c}\mathrm{t} \text { : Co-creation } \\
\text { of Value }\end{array}$ & $\begin{array}{c}\text { t: Service } \\
\text { Importance }\end{array}$ \\
\hline AllServices & .366 & .347 & .053 & 14.594 & 2.208 \\
DomesticTransfer & .273 & .265 & -.076 & 3.948 & -1.137 \\
YenDeposit & .298 & .297 & .004 & 4.425 & .054 \\
InternetBanking & .292 & .295 & -.020 & 4.366 & -.294 \\
TradeFinance & .494 & .377 & .198 & 5.645 & 2.965 \\
GCMS & .496 & .378 & .225 & 5.940 & 3.543 \\
I-Bank & .521 & .462 & .140 & 7.418 & 2.241 \\
ShortTermLoan & .320 & .281 & .086 & 4.022 & 1.231 \\
LongTermLoan & .311 & .262 & .099 & 3.693 & 1.391 \\
\hline
\end{tabular}

a. Predictors: (Constant), Co-creation of Value, ServiceImportance

b. Dependent Variable: SwitchingCosts

Examining the regression analysis result for each of the eight services, it is observed that co-creation of value has stronger influence on switching costs than service importance. The beta for co-creation of value is mostly at .3 level or higher while the beta for service importance is mostly at .1 level or lower.

As previously argued in this study, a bank that is trying to obtain a main bank or a main supplier position with a corporate customer should target services with large co-creation of value and small switching costs. When the eight financial services are mapped in a scatter diagram with switching costs and co-creation of value on its axes, no service is clearly positioned in that quadrant, as shown in Figure 5. Trade finance, a target service candidate suggested by bank managers, turned out to represent relatively low co-creation of value. Domestic transfer and yen deposit could be arguably considered as candidate services for such purposes. 


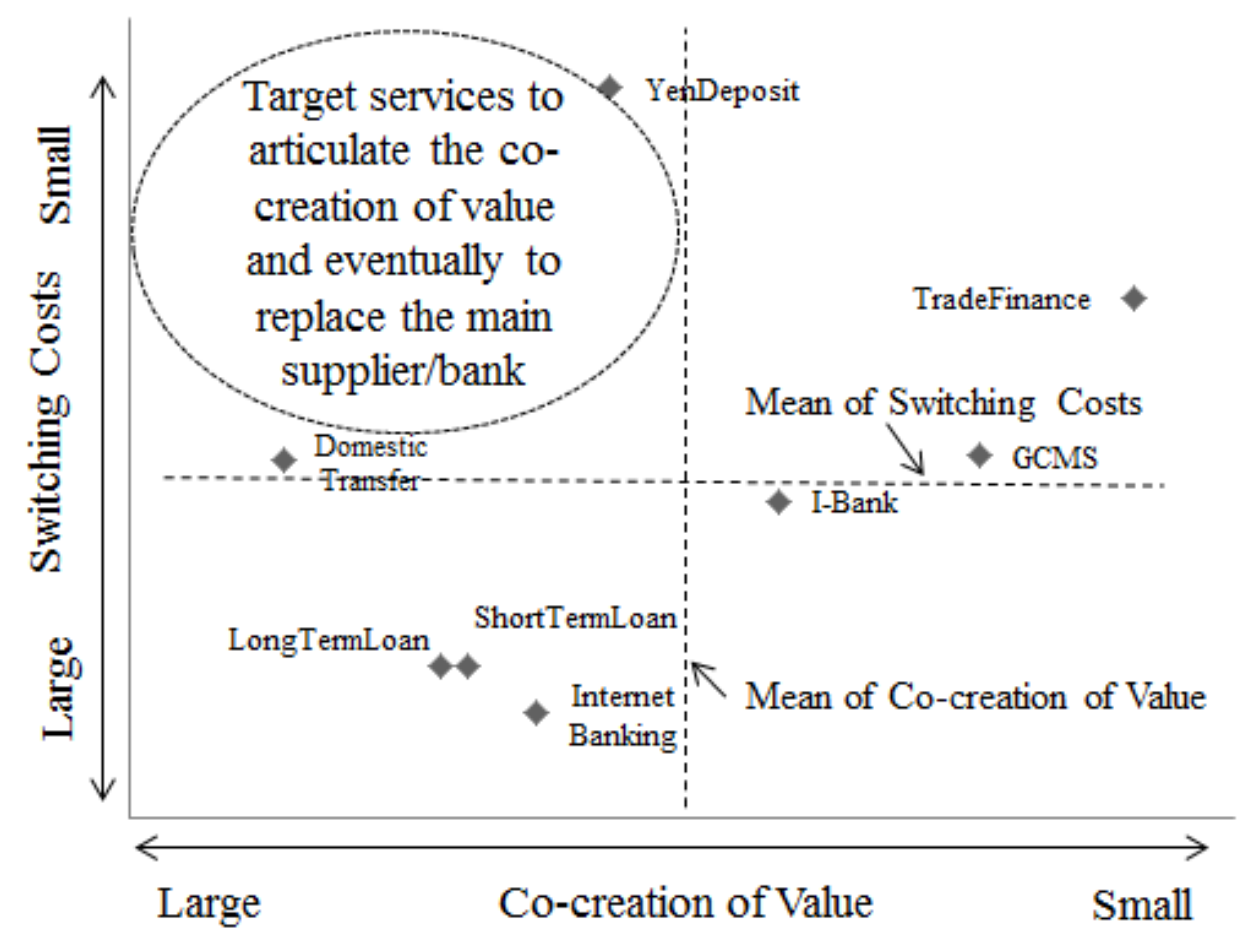

Figure 5: Scatter Diagram Of The Eight Services

Hypothesis 4: Indirect value and co-creation of value are associated with higher customer share than direct value and co-creation of value.

This hypothesis is relatively well supported. The multiple regression analysis for all services that have customer share as a dependent variable and indirect value and direct value as independent variables provides very low beta (.011) and a $t$-value (.348) for direct value, whereas it provides much higher beta (.196) and $t$-value (6.054) for indirect value, with $r$ of .543 , as shown in Table 8 . 
Table 8: Regression Analysis On Hypothesis 4

\begin{tabular}{|c|c|c|c|c|c|c|c|}
\hline Service & $\mathrm{R}^{\mathrm{a}}$ & $\begin{array}{c}\text { Beta }{ }^{b} \text { : } \\
\text { Co- } \\
\text { creation } \\
\text { of Value }\end{array}$ & $\begin{array}{l}\text { Beta }{ }^{b} \text { : } \\
\text { Indirect } \\
\text { Values }\end{array}$ & $\begin{array}{l}\text { Beta }{ }^{b} \\
\text { Direct } \\
\text { Values }\end{array}$ & $\begin{array}{l}\mathrm{t}: \mathrm{Co}- \\
\text { creation } \\
\text { of Value }\end{array}$ & $\begin{array}{l}\text { t: Indirect } \\
\text { Values }\end{array}$ & $\begin{array}{c}\mathrm{t} \text { : Direct } \\
\text { Values }\end{array}$ \\
\hline $\begin{array}{l}\text { All } \\
\text { Services }\end{array}$ & .543 & .406 & .196 & .011 & 16.561 & 6.054 & .348 \\
\hline $\begin{array}{l}\text { Domestic } \\
\text { Transfer }\end{array}$ & .525 & .444 & .175 & -.028 & 6.812 & 2.121 & -.347 \\
\hline $\begin{array}{l}\text { Yen } \\
\text { Deposit }\end{array}$ & .481 & .417 & .101 & .030 & 6.132 & 1.261 & .373 \\
\hline $\begin{array}{l}\text { Internet } \\
\text { Banking }\end{array}$ & .544 & .400 & .221 & .015 & 6.009 & 2.662 & .178 \\
\hline $\begin{array}{l}\text { Trade } \\
\text { Finance }\end{array}$ & .613 & .402 & .320 & -.061 & 5.534 & 2.850 & -.602 \\
\hline GCMS & .559 & .450 & .183 & -.027 & 6.241 & 1.666 & -.257 \\
\hline I-Bank & .535 & .385 & .224 & -.014 & 5.319 & 2.205 & -.144 \\
\hline $\begin{array}{l}\text { Short } \\
\text { TermLoan }\end{array}$ & .501 & .371 & .164 & .029 & 4.999 & 1.754 & .320 \\
\hline $\begin{array}{l}\text { Long } \\
\text { TermLoan }\end{array}$ & .490 & .363 & .172 & .016 & 4.860 & 1.838 & .175 \\
\hline
\end{tabular}

This suggests that a corporate customer places much higher priority on indirect value, which they believe enables larger benefits in the long run, considering the share of each service provider.

Examining the regression analysis result for each of the eight services, it is observed that three services have $r$ greater than .5 , with $t$-values larger than 2 - domestic transfer, Internet banking and trade finance. This suggests that, particularly with these three services, an enterprise should provide trustful information for its customers, fully understand its customers' businesses and always be responsive to inquiries from customers, rather than putting itself in a price war in terms of interest rates or fees, judging from the key dimensions of the indirect value in the conceptualisation. In other words, an enterprise must understand that its customer appreciates reliability, empathy and responsiveness in the long run, rather than a short-term price discount.

Lastly, the final regression analysis is conducted on a step-wise basis for all services that have customer share as a dependent variable and all other potential variables as independent variables, including implementation of co-creation of value activities, co-creation of value, indirect values, service importance, direct values and switching costs, as shown in Table 9. In particular, this analysis focuses on the effect of switching costs on customer share. 
Table 9: Regression Analysis On All Variables

\begin{tabular}{ccccc}
$\begin{array}{c}\text { Model S ummary } \\
\text { Model }\end{array}$ & $\mathrm{R}$ & R Square & Adjusted R Square & $\begin{array}{c}\text { Std. Error of the } \\
\text { Estimate }\end{array}$ \\
\hline 1 & $.547^{\mathrm{a}}$ & .299 & .298 & 1.352 \\
2 & $.596^{\mathrm{b}}$ & .355 & .354 & 1.297 \\
3 & $.603^{\mathrm{c}}$ & .363 & .362 & 1.289 \\
4 & $.607^{\mathrm{d}}$ & .368 & .367 & 1.284 \\
5 & $.612^{\mathrm{e}}$ & .374 & .372 & 1.278 \\
a. Predictors: (Constant), ImplementatingCoValueCreatrion & \\
b. Predictors: (Constant), ImplementatingCoValueCreatrion, CoValueCreation \\
c. Predictors: (Constant), ImplementatingCoValueCreatrion, CoValueCreation, Indirect Value \\
d. Predictors: (Constant), ImplementatingCoValueCreatrion, CoValueCreation, Indirect Value, ServiceImportance \\
e. Predictors: (Constant), ImplementatingCoValueCreatrion, CoValueCreation, Indirect Value, ServiceImportance, CredenceQualities
\end{tabular}

Coefficients $^{\mathrm{a}}$

\begin{tabular}{|c|c|c|c|c|}
\hline Model & & Beta & $\mathrm{t}$ & Sig. \\
\hline \multirow{2}{*}{1} & (Constant) & & 29.511 & .000 \\
\hline & Implementating CoValueCreation & .547 & 26.668 & .000 \\
\hline \multirow{3}{*}{2} & (Constant) & & 21.926 & .000 \\
\hline & Implementating CoValueCreation & .372 & 15.254 & .000 \\
\hline & CoValueCreation & .295 & 12.100 & .000 \\
\hline \multirow{4}{*}{3} & (Constant) & & 17.407 & .000 \\
\hline & Implementating CoValueCreation & .338 & 13.362 & .000 \\
\hline & CoValueCreation & .256 & 10.002 & .000 \\
\hline & Indirect Values & .111 & 4.630 & .000 \\
\hline \multirow{5}{*}{4} & (Constant) & & 16.652 & .000 \\
\hline & Implementating CoValueCreation & .321 & 12.519 & .000 \\
\hline & CoValueCreation & .253 & 9.901 & .000 \\
\hline & Indirect Values & .094 & 3.836 & .000 \\
\hline & Service Importance & .078 & 3.649 & .000 \\
\hline \multirow{6}{*}{5} & (Constant) & & 12.025 & .000 \\
\hline & Implementating CoValueCreation & .322 & 12.592 & .000 \\
\hline & CoValueCreation & .241 & 9.384 & .000 \\
\hline & Indirect Values & .081 & 3.322 & .001 \\
\hline & Service Importance & .090 & 4.178 & .000 \\
\hline & CredenceQualities & .079 & 3.951 & .000 \\
\hline
\end{tabular}

a. Dependent Variable: CustomerShare

As a result, even at the final Model 5, direct values and switching costs are excluded from the model. Although exclusion of direct values is well expected due to the analyses of Hypothesis 4, interestingly, switching costs turn out to have very little or no impact on customer share. This suggests that an enterprise should not let its guard down, even for services with high switching costs. An enterprise may not lose a customer due to high switching costs of these services, but it may not be able to achieve a position of a leading supplier because a customer does not place a high priority on switching costs when they determine the share of each supplier.

Interestingly, but not surprisingly, the implementation of co-creation of value efforts has the largest impact on customer share by far. The $r$ of Model 1 is already .547 by having only one independent variable of 
implementation of co-creation of value, and the $r$ of the final Model 5 is still .612 with five independent variables in total, which is only marginally larger than .547. This emphasises and reinforces the power of implementation in a real business world with such statistical analysis.

\section{CONCLUSIONS}

The findings in this study provide insight into the complex interrelationships among co-creation of value, switching costs and customer share constructs.

The results show that credence qualities and service importance are positively related to the co-creation of value, which consists of emotional value, monetary value and knowledge value. When implementing the co-creation of value, an enterprise needs to understand credence qualities for each service they provide so it can prioritise its implementation efforts. Similar to this result, service importance and co-creation of value are positively related to switching costs, which are in the form of learning costs, economic costs, evaluation costs and set-up costs. Although switching costs help an enterprise to retain its customers (Gronhaug \& Gilly, 1991; Edward \& Sahadev, 2011), they appear not to have any impact on customer share. In addition, indirect values have a much larger impact on customer share than direct values, presumably because customers place higher priority on indirect values that benefit them in the long run.

The conceptual model in this study highlights the mediating role of co-creation of value on customer share, focusing on the interrelationships of co-creation of value, switching costs and customer share in the BtoB environment. Prior research has examined the relationships within subsets of these constructs, mainly in the BtoC environment (Lam et al., 2004). By invoking the well-investigated conceptual framework, shown in Figure 1, this study provides a theoretical justification to define co-creation of value and indirect values as causes and customer share as an effect.

The author does not find good support for a positive impact of co-creation of value prior to value exchange on the overall size of co-creation of value. The idea for this relationship comes from the face-to-face interviews with bank managers and the author's own business experiences of over 20 years. The non-significant finding for this relationship could be due to the questionnaire setting used.

\section{LIMITATIONS AND FUTURE RESEARCH}

As in any empirical research, the results of this study must be interpreted in view of certain limitations, which offer opportunities for future research.

First, the data are from the BtoB financial industry that embodies some common characteristics of service industries in the BtoB context, such as long-term orientation, repeated purchase from a limited number of suppliers and a wide variety of service offerings. Although such focus on a single industry helps keep unexplained variance or 'noise' small in the model estimation and the hypothesis testing, it may limit the generalisability of the results. Future research may replicate this study in other industries, such as information technology, logistics, consulting and business personnel services.

Second, the sample size $(\mathrm{N}=209)$ from the corporate managers who take charge of their banking relationships is not representative of the whole population of neither financial institutions nor services companies in general. A randomised sample using other sources, such as large industry databases, with support from a multiple number of research companies, could be used, although it may be a costly option for a researcher. In addition, a replication of the study in other countries would allow for cross-border validation of the results.

Third, although a number of variables are collected in this study, variables such as power of sales and function of account managers, which this study did not examine, may also moderate the interrelationships of cocreation of value, switching costs and customer share. Salomonson, Aberg, and Allwood (2012) examine the communication capabilities by account managers, and Terho, Haas, Eggert, and Ulaga (2012) suggest a different sales approach in the BtoB context. In addition, this study has not formally addressed the key construct of customer 
satisfaction in its conceptual framework. Future research may attempt to more rigorously examine additional variables and constructs, such as the impact of sales and account managers and customer satisfaction.

Fourth, this study adopts a static view of interrelationships of key constructs, capturing a 'snapshot' of corporate customers' perspectives of relationships with their service suppliers at a given point of time. Researchers could measure benefits and challenges over the lifetime of a business relationship and calculate its net present value.

\section{ACKNOWLEDGMENTS}

The author would like to thank two anonymous bank managers and four corporate managers for their invaluable comments on the questionnaire questions and the hypotheses in this study.

\section{AUTHOR INFORMATION}

Yoshiaki Watanabe is an Associate Professor of MBA-IB Program of University of Tsukuba, teaching Business Strategy, Cross-cultural Management, Corporate Social Responsibility, Case-study Seminar and others. Prior to that, he was the Representative Director of SWIFT Japan Ltd. He received an MBA from Darden Graduate School of Business Administration of University of Virginia. E-mail: watanabey92@alum.darden.edu.

\section{REFERENCES}

1. Burnham, T. A., Frels, J. K., \& Mahajan, V. (2003). Consumer Switching Costs: A Typology, Antecedents, and Consequences. Journal of the Academy of Marketing Science, 31(2), 109-126.

2. Cronbach, L. J. (1951). Coeedicient Alpha and the Internal Structure of Tests. Psychometrika, 16(3), 297334.

3. Curto, J.C. \& Pinto, J.D. (2011). The corrected VIF (CVIF). Journal of Appkied Statistics, 38(7), 14991507.

4. Edward, M. \& Sahadev, S. (2011). Role of swutching costs in the service quality, perceived value, customer satisfaction and customer retention linkage. Asia Pacific Journal of Marketing and Logistics, 23(3), 327-345.

5. $\quad$ Eggert, A. \& Ulaga, W. (2008). Linking Customer Value to Customer Share in Business Relationships. Advances in Business Marketing and Purchasing, 14, 221-247.

6. Eggert, A. \& Ulaga, W. (2010). Managing customer share in key supplier relationships. Industrial Marketing Management, 39, 1346-1355.

7. Eisingerich, A. B. \& Bell, S. J. (2007). Maintaining customer relationships in high credence services. Journal of Services Marketing, 21(4), 253-262.

8. Frow, P., Payne, A., \& Storbacka, K. (2011). Co-Creation: A Typology and Conceptual Framework. Proceedings of ANZMAC 2011, Perth, 1-6.

9. Fujikawa, Y., Akutsu, S., \& Ono, J. (2012). Management by co-creation of value: In preparation for development of dynamic process model. Organization Science/Soshiki Kagaku, 46(2), 38-52.

10. Gao, T., Sirgy, M. J., \& Bird, M. M. (2005). Enriching Customer Value Research with a Relational Perspective: Evidence from an Empirical Investigation of Organizational Buyer's Value Perceptions. Journal of Relationship Marketing, 4(1/2), 21-42.

11. Grönroos, C. (2005). What Can A Service Logic Offer Marketing Theory. Working Papers 508, Swedish School of Economics and Business Administration, Department of Marketing and Corporate Geography, 125 .

12. Gronhaug, K. \& Gilly, M.C. (1991). A transaction cost approach to consumer dissatisfaction and complaint actions. Journal of Economic Psychology, 12, 165-183

13. Inoue, T. (2013). Circumstances around Service-Dominant Logic. Japan Marketing Academy, The $2^{\text {nd }}$ Marketing Conference 2013, November 10, 2013

14. Jones, M. A., Mothersbaugh, D. L., \& Beatty, S. E. (2000). Switching Barriers and Repurchase Intentions in Services. Journal of Retailing, 76(2), 259-274.

15. Kellar, G. M. \& Preis, M. W. (2011). Satisfaction and repurchase intention: B2B buyer-seller relationships in medium-technology industries. Academy of Information and Management Sciences Journal, 14(2), 11- 
19.

16. Lam, S. Y., Shanker, V., Erramilli, M. K., \& Murphy, B. (2004). Customer Value, Satisfaction, Loyalty, and Switching Costs: An Illustration From a Business-to-Business Service Context. Journal of the Academy of Marketing Science, 32(3), 293-311.

17. Lusch, R. F. \& Vargo, S. L. (2006). Service-dominant logic: reactions, reflections and refinements. Marketing Theory, 6(3), 281-288.

18. Menard, S. W. (1995). Applied logistic regression alalysis. Sage Publications, London

19. Mittal, V., Ross, T. W. Jr., \& Baldasare, P. M. (1998). The Asymmetric Impact of Negative and Positive Attribute-Level Performance on Overall Satsfaction and Repurchase Intentions. Journal of Marketing, 62, 33-47.

20. Normann, R. \& Remirez, R. (1993). From Value Chain to Value Constellation: Designing Interactive Strategy. Harvard Business Review, 71(4), 65-77.

21. Parasuraman, A., Berry, L. L., \& Zeithaml, V. A. (1991). Refinement and Reassessment of the SERVQUAL Scale. Journal of Retailing, 67(4), 420-450.

22. Patterson, G. P. \& Spreng, R. A. (1997). Modelling the relationship between perceived value, satsfaction and repurchase intentions in a business-to-business, services context: an empirical examination. International Journal of Service Industry Management, 8(5), 414-434

23. Salomonson, N., Aberg, A., \& Allwood, J. (2012). Communicative skills that support value creation: A study of B2B interactions between customers and customer service representatives. Industrial Marketing Management, 41, 145-155.

24. Spreng, R. A., Shi, A. H., \& Page, T. J. (2009). Service quality and satisfaction in business-to-business services. Journal of Business \& Industrial Marketing, 24(8), 537-548.

25. Terho, H., Haas, A., Eggert, A., \& Ulaga, W. (2012). 'It's almost like taking the sales out of selling'Towards a conceptualization of value-based selling in business markets. Industrial Marketing Management, $41,174-185$

26. Toya, K. (2013). Considerations on the structure of co-creation of value. Japan Marketing Journal, 33(3), $32-45$.

27. Vargo, S. L. \& Lusch, R. F. (2004). Evolving to a New Dominat Logic for Marketing. Journal of Marketing, 68, 1-17.

28. Vargo, S. L. \& Lusch, R. F. (2008a). Service-dominant logic: continuing the evolution. Journal of the Academy of Marketing Science, 36, 1-10.

29. Vargo, S. L. \& Lusch, R. F. (2008b). es(s): Divergences and convergences of logics. Industrial Marketing Management, 37, 254-259.

30. Vargo, S. L. \& Lusch, R. F. (2011). It's all B2B... and beyond: Toward a systems perspective of the market. Industrial Marketing Management, 40, 181-187.

31. Walter, A., Ritter, T., \& Gemünden, H. G. (2001). Value Creation in Buyer-Seller Relationships. Industrial Marketing Management, 30, 365-377.

32. Zeithaml, V. A. \& Bitner, M. J. (1996). Services Marketing (3rd ed.). McGraw-Hill/Irwin.

33. Zhang, Y., Fang, Y., Wei, K-K., Ramsey, E., McCole, P., \& Chen, H. (2011). Repurchase intention in B2C e-commerce - A relationship quality perspective. Information \& Management, 48, 192-200. 